\title{
ВАРІАБЕЛЬНІСТЬ СЕРЦЕВОГО РИТМУ ПРИ ХРОНІЧНІЙ СЕРЦЕВІЙ НЕДОСТАТНОСТІ ЗІ ЗБЕРЕЖЕНОЮ ФРАКЦІЮЮ ВИКИДУ
}

\author{
○Я. О. Андреєва, Д. П. Мирний \\ ДЗ «Запорізька медична академія післядипломної освіти МОЗ України»
}

PЕзюмЕ. Серцева недостатність залишається основною причиною передчасної смерті та низької якості життя у пацієнтів з різними кардіоваскулярними захворюваннями.

Мета - дослідити зміни варіабельності серцевого ритму у хворих з серцевою недостатністю зі збереженою фракцією викиду.

Матеріал і методи. Обстежено 98 осіб з СНзЗФВ І-ІІА стадії І-ІІ функціональних класів згідно з класифікацією NYHA (53 чоловіки та 45 жінок) віком від 19 до 66 років. Усім учасникам дослідження проведено загальноклінічне обстеження з обов'язковим вимірюванням окружності талії та стегон, ваги та зросту, ехокардіографія, добове моніторування ЕКГ.

Результати. В усіх пацієнтів з СНзЗФВ було зареєстровано зміни ВСР протягом доби і ригідний циркадний ритм ЧСС. Спостерігалось патологічне збільшення спектральних показників VLF, LF, LFN як у денний, так і у нічний час. Достатнього зниження спектральних показників VLF, LF, LFN у нічний час у основній групі не відбувалось. Не фіксувалось достатнього підйому HF та HFN у нічний час, на відміну від контрольної групи. Співвідношення LF/HF було достовірно збільшене у хворих з СНзЗФВ. При кореляційному аналізі встановлено негативний кореляційний зв'язок віку з SDNN ( $r=-0,336, p<0,05)$, RMSSD $(r=-0,312, p<0,05), p N N 50(r=-0,377, p<0,05), H F(r=-0,418, p<0,05)$ та позитивний кореляційний зв'язок зі співвідношенням LF/HF $(r=0,384, p<0,05)$. SDNN корелював із часом уповільнення кровотоку раннього діастолічного наповнення лівого шлуночка $(r=-0,418, p<0,05)$ та часом ізоволюметричного розслаблення $(r=-0,436, p<0,05)$.

Висновки. Розвиток хронічної серцевої недостатності зі збереженою фракцією викиду супроводжується зниженням загальної варіабельності серцевого ритму. У хворих з серцевою недостатністю зі збереженою фракцією викиду, порівняно зі здоровими особами, спостерігається зниження тонусу парасимпатичної ланки вегетативної нервової системи і збільшення тонусу симпатичної вегетативної ланки. За результатами однофакторного регресійного аналізу встановлено взаємозв'язок спектрального показника SDNN та часу ізоволюметричного розслаблення.

КлючОВІ СлОВА: серцева недостатність; серцевий ритм; фракція викиду; нервова система.

Вступ. Серцева недостатність (СН) залишається основною причиною передчасної смерті та низької якості життя у пацієнтів з різними кардіоваскулярними захворюваннями [1]. Незважаючи на значні успіхи у вивченні патофізіології СН та істотний прогрес у галузі фармакотерапії, це захворювання все ще залишається найпоширенішою причиною розвитку ускладнень і смертності, величезним тягарем для національних систем охорони здоров'я [2]. Згідно з даними великих епідеміологічних досліджень, СН може формуватися і при нормальній фракції викиду (ФВ) лівого шлуночка (ЛШ). При цьому питома вага пацієнтів, які страждають СН зі збереженою ФВ ЛШ (СНз3ФВ), досягає половини від загальної чисельності хворих з СН. На відміну від прогнозу при СН зі зниженою ФВ ЛШ, прогноз при СНзЗФВ за останні десятиліття не покращився. Досі переважна більшість патогенетичних механізмів та методів ефективного лікування при СНзЗФВ досліджені недостатньо [3].

Відповідно до сучасної моделі патогенезу хронічної $\mathrm{CH}$, цей стан, перш за все, розглядають як патологію нейрогуморальних механізмів регуляції кровообігу [4]. Автономна дисфункція $\epsilon$ типовою ознакою хронічної серцевої недостат- ності та пов'язана з тяжкістю захворювання і прогнозом при хронічній серцевій недостатності. Кількісно охарактеризувати активність симпатичного і парасимпатичного відділів вегетативної нервової системи можна при аналізі варіабельності серцевого ритму (ВСР) [5]. ВСР у хворих з XСН досліджено досить добре, але диференційної оцінки стану ВСР у хворих із СНз3ФВ не проводилось.

Мета - дослідити зміни варіабельності серцевого ритму у хворих з серцевою недостатністю зі збереженою фракцією викиду.

Матеріал і методи дослідження. Обстежено 98 осіб з серцевою недостатністю (53 чоловіки та 45 жінок) віком від 19 до 66 років, які перебували на стаціонарному лікування в КУ «Центральна лікарня Комунарського району м. Запоріжжя». В усіх пацієнтів було діагностовано СНзЗФВ І-ІІА стадії I-ІІ функціональних класів згідно з класифікацією NYHA. Осіб з ендокринною, пульмонологічною та іншими клінічно значущими захворюваннями, пацієнтів, що приймали $\beta$-адреноблокатори, було виключено з дослідження.

До контрольної групи увійшли 25 практично здорових осіб (13 чоловіків та 12 жінок) (табл. 1). 
Огляди літератури, оригінальні дослідження, погляд на проблему

Таблиця 1. Клінічна характеристика обстежених осіб

\begin{tabular}{|l|c|c|c|}
\hline \multicolumn{1}{|c|}{ Показник } & Основна група $(n=98)$ & Контрольна група $(n=25)$ & Достовірність \\
\hline Вік, років & $43,6 \pm 8,7$ & $41,2 \pm 3,6$ & $\mathrm{p}>0,05$ \\
\hline Чоловіки/жінки, осі6 & $53 / 45$ & $13 / 12$ & $\mathrm{p}>0,05$ \\
\hline ІМТ, кг/м² & $31,4 \pm 2,2$ & $22,8 \pm 2,2$ & $\mathrm{p}<0,05$ \\
\hline Окружність талії, см & $98,6 \pm 7,1$ & $80,3 \pm 6,9$ & $\mathrm{p}<0,05$ \\
\hline Окружність стегон, см & $124,2 \pm 8,4$ & $91,4 \pm 6,3$ & $\mathrm{p}<0,05$ \\
\hline ОТ/ОС, у. о. & $1,07 \pm 0,3$ & $0,96 \pm 0,09$ & $\mathrm{p}>0,05$ \\
\hline ФВ, \% & $62,2 \pm 4,3$ & $69,4 \pm 5,5$ & $\mathrm{p}>0,05$ \\
\hline
\end{tabular}

Дослідження проведене відповідно до основних біоетичних норм Гельсінської декларації Всесвітньої медичної асоціації про етичні принципи проведення науково-медичних досліджень із поправками (2000, 3 поправками 2008). Протокол дослідження було затверджено етичним комітетом ДЗ "ЗМАПО МОЗ України". Письмова інформована згода була отримана у кожного учасника дослідження.

Усім учасникам дослідження проведено загальноклінічне обстеження 3 обов'язковим вимірюванням окружності талії та стегон, ваги та зросту, ехокардіографія, добове моніторування ЕКГ.

Діагностику СНзЗФВ проводили відповідно до рекомендацій Европейської асоціації кардіологів [4]. Трансторакальна ехокардіографія була проведена за допомогою апарату Siemens ACUSONX300 здатчиком 1,75 МГцв М-модальному і двомірному режимах в стандартних ехографічних позиціях з використанням імпульсної і постійнохвильової доплерографії і кольорового доплерівського картування.

Дослідження варіабельності серцевого ритму здійснили згідно з рекомендаціями, що були ухвалені робочою групою Європейського товариства кардіологів із вивчення даних статистичного та спектрального аналізу показників кардіоритмограми на апараті КардіоСенс (ХАІ-Медика, Україна). Програма автоматично розраховувала середню (ЧССср), мінімальну і максимальну частоту серцевих скорочень (ЧССмах, чССmin) вдень i вночі, денну і нічну потужність спектрів дуже низьких (VLF), низьких (LF) і високих (HF) частот, виражені як в абсолютних, так і в нормалізованих одиницях (LFN, HFN), їх співвідношення (LF/ HF), а також повну потужність спектра (ТP), стандартне відхилення сусідніх RR-інтервалів (SDNN), відсоток різниць між сусідніми RR-інтервалами, що відрізняються більш ніж на 50 мс (NN50) і корінь квадратний із середньої суми квадратів різниць між наступними RR-інтервалами (RMSSD), середню тривалість інтервалів RR (mRR).

Кількісні змінні представлено як середнє значення і стандартне відхилення середнього арифметичного (M $\pm S D)$. Категоричні змінні були представлені у відсотках. Відмінності кожної змінної оцінювали за допомогою t-тесту Student для безперервних змінних та тесту $\chi^{2}$ для категоричних змінних. Співвідношення між параметрами оцінювали за допомогою кореляційного аналізу Пірсона та однофакторного регресійного аналізу. Вважали, що значення $\mathrm{P}<0,05$ вказують на статистично значущу різницю між групами. Розрахунки проводили за допомогою SPSS-програмного забезпечення (версія 22.0; SPSS, Чикаго, IL).

Результати й обговорення. В усіх пацієнтів з СНзЗФВ було зареєстровано зміни ВСР протягом доби і ригідний циркадний ритм ЧСС. Динаміка ЧСС характеризувалась відсутністю достовірного зниження чССсер в обстежених групах, порівняно з контрольною групою $(p<0,05)$, та більшими показниками ЧСCcep, ЧCCmax і чCCmin у пацієнтів основної групи, порівняно з контрольною групою $(p<0,05)$ (табл. 2).

Таблиця 2. Показники варіабельності серцевого ритму протягом доби у обстежених осіб

\begin{tabular}{|c|c|c|c|c|}
\hline \multirow[t]{2}{*}{ Показник } & \multicolumn{2}{|c|}{$\begin{array}{c}\text { Основна група } \\
(n=98)\end{array}$} & \multicolumn{2}{|c|}{$\begin{array}{c}\text { Контрольна група } \\
(n=25)\end{array}$} \\
\hline & день & Hí & день & ніч \\
\hline 1 & 2 & 3 & 4 & 5 \\
\hline \multirow[t]{2}{*}{ SDNN, MC } & $33,4 \pm 5,4$ & $24,3 \pm 6,2$ & \multirow{2}{*}{$49,6 \pm 12,4$} & \multirow{2}{*}{$38,5 \pm 11,3$} \\
\hline & $R_{K}=0,031$ & $R_{K}=0,011$ & & \\
\hline \multirow[t]{2}{*}{ RMSSD, MC } & $27,3 \pm 6,4$ & $34,5 \pm 8,8$ & \multirow{2}{*}{$43,7 \pm 11,2$} & \multirow{2}{*}{$62,4 \pm 12,3$} \\
\hline & $R_{K}=0,010$ & $R_{k}=0,012$ & & \\
\hline \multirow[t]{2}{*}{ pNN50, \% } & $7,8 \pm 4,9$ & $17,6 \pm 5,1$ & \multirow{2}{*}{$12,6 \pm 6,1$} & \multirow{2}{*}{$28,4 \pm 7,3$} \\
\hline & $R_{K}=0,008$ & $R_{K}=0,001$ & & \\
\hline
\end{tabular}


Продовження табл. 2

\begin{tabular}{|c|c|c|c|c|}
\hline 1 & 2 & 3 & 4 & 5 \\
\hline \multirow{2}{*}{$L F, M C^{2}$} & $522,7 \pm 30,7$ & $489,8 \pm 32,8$ & \multirow{2}{*}{$410,1 \pm 60,3$} & \multirow{2}{*}{$459,2 \pm 31,4$} \\
\hline & $R_{k}=0,006$ & $R_{k}=0,007$ & & \\
\hline \multirow{2}{*}{ LFN, \% } & $63,2 \pm 8,4$ & $55,1 \pm 6,2$ & \multirow{2}{*}{$43,7 \pm 9,9$} & \multirow{2}{*}{$46,7 \pm 9,9$} \\
\hline & $R_{K}=0,002$ & $R_{k}=0,004$ & & \\
\hline \multirow{2}{*}{$\mathrm{HF}, \mathrm{MC}^{2}$} & $161,7 \pm 18,2$ & $188,2 \pm 11,6$ & \multirow{2}{*}{$221,1 \pm 18,6$} & \multirow{2}{*}{$301,1 \pm 29,6$} \\
\hline & $R_{K}=0,021$ & $R_{K}=0,008$ & & \\
\hline \multirow{2}{*}{ HFN, \% } & $23,2 \pm 5,1$ & $29,1 \pm 4,8$ & \multirow{2}{*}{$34,2 \pm 7,3$} & \multirow{2}{*}{$37,6 \pm 8,2$} \\
\hline & $R_{K}=0,031$ & $R_{k}=0,037$ & & \\
\hline \multirow{2}{*}{ LF/HF, ум. од. } & $3,6 \pm 0,7$ & $2,22 \pm 1,1$ & \multirow{2}{*}{$1,0 \pm 0,8$} & \multirow{2}{*}{$0,9 \pm 0,2$} \\
\hline & $R_{K}=0,034$ & $R_{K}=0,021$ & & \\
\hline \multirow{2}{*}{$\operatorname{TP}\left(M C^{2}\right)$} & $1721,6 \pm 102,2$ & $1361,3 \pm 108,3$ & \multirow{2}{*}{$2089,7 \pm 135,7$} & \multirow{2}{*}{$3148,4 \pm 122,9$} \\
\hline & $R_{K}=0,001$ & $R_{k}=0,001$ & & \\
\hline
\end{tabular}

SDNN та RMSSD у пацієнтів основної групи були достовірно нижчі, ніж у контрольній, як вдень, так і вночі $(p<0,05)$. Показник SDNN у пацієнтів з СНзЗФВ був нижчим, ніж у контрольній, на $32,6 \%$ у денний час і на $36,9 \%$ у нічний час $(p<0,05)$. Значення рNN50 у основній групи також достовірно відрізнялось від показників контрольної групи у денний та нічний час та було нижчим на $38,1 \%$ i 38,3 \% відповідно. Спостерігалось патологічне збільшення спектральних показників VLF, LF, LFN як у денний, так і у нічний час. Достатнього зниження спектральних показників VLF, LF, LFN у нічний час у основній групі не відбувалось $(p<0,05)$. Потужність спектрів високих частот в пацієнтів 3 СНзЗФВ була достовірно нижча, ніж у контрольній групі. Також не фіксувалось достатнього підйому HF та HFN у нічний час, на відміну від контрольної групи. Співвідношення LF/HF відповідно було достовірно збільшене у хворих з СНзЗФВ.

При кореляційному аналізі між показниками ВСР та іншими показниками у осіб з СНзЗФВ було встановлено наступні зміни. Виявлено негативний кореляційний зв'язок віку з SDNN $(r=-0,336, p<0,05)$, RMSSD $(r=-0,312, p<0,05)$, pNN50 $(r=-0,377, p<0,05)$, HF $(r=-0,418, p<0,05)$ та позитивний кореляційний зв'язок зі співвідношенням LF/HF $(r=0,384, p<0,05)$. Між ФВ та ВСР у групах хворих з СНзЗФВ встановлено позитивний кореляційний зв'язок із SDNN $(r=0,315, p<0,05)$. Цей показник також корелював із часом уповільнення кровотоку раннього діастолічного наповнення лівого шлуночка $(r=-0,418, p<0,05)$ та часом ізоволюметричного розслаблення $(r=-0,436, p<0,05)$. При проведенні однофакторного регресійного аналізу встановлено зв'язки лише між показником SDNN і віком (ВШ 1,26 (0,99-1,37), $p<0,05)$, SDNN і час ізоволюметричного розслаблення (ВШ 1,16 $(0,85-1,24), p<0,05)$.

Таким чином, за результатами нашого дослідження у всіх осіб із СНзЗФВ, порівняно зі здоро- вими особами, встановлено достовірні зміни як спектральних, так і частотних показників. У всіх пацієнтів було зареєстровано зменшення загальної потужності коливань серцевого ритму (Т). Найбільш виразні зміни зареєстровано для частотних показників. Так, реєструвалось збільшення індексу LF та зниження індексу HF, що свідчить про відносне збільшення активності симпатичної нервової системи на фоні зниження парасимпатичної активності як удень, так і вночі. Показник SDNN мав тісний позитивний кореляційний зв'язок з часом ізоволюметричного розслаблення та часом уповільнення кровотоку раннього діастолічного наповнення лівого шлуночка. Встановлений за даними однофакторного регресійного аналізу у нашому дослідженні взаємозв'язок між SDNN та показниками діастолічної дисфункції може бути пов'язаний зі зниженням загального вегетативного тонусу вже на етапі змін діастолічної функції міокарда ЛШ без погіршення систолічної функції міокарда. Найвиразніші зміни було зареєстровано у спектрі коливань HF. Достовірні зміни у спектрі дуже повільних коливань (VLF) у пацієнтів з СНзЗФВ вказували на однаковий вплив як нервово-рефлекторної, так і гуморальної регуляції.

Отримані результати можна пояснити первісним підвищенням активності симпатичної нервової системи при СН, що має компенсаторний характер, оскільки воно сприяє підвищенню серцевого викиду і перерозподілу регіонарного кровотоку у бік серця і скелетної мускулатури. При цьому ниркова вазоконстрикція призводить до затримки натрію і рідини, що покращує перфузію життєво важливих органів [1]. Достовірне зниження основних часових показників ВСР при ХСН свідчить про тісний зв'язок стану екстракардіальної регуляції серцевого ритму і функціонального стану серця у патогенезі розвитку і прогресування $\mathrm{CH}$. 
Оцінка змін ВСР при серцевій недостатності проведена у ряді робіт. Так, Rydlewska A. et al. [6] провели порівняльний аналіз варіабельності серцевого ритму при компенсованій та некомпенсованій серцевій недостатності і встановили прогресуюче зниження ВСР у хворих з СН при збільшенні тяжкості захворювання і підвищення цього показника на фоні терапії. Результати Rydlewska A. et al. збігаються з результатами нашого дослідження, а саме встановленим зниженням варіабельності серцевого ритму у хворих з $\mathrm{CH}$.

Атаходжаєва Г. А. и соавт. [7] провели оцінку стану ВСР у хворих на СН та метаболічний синдром і встановили зниження загальної ВСР, що збігаєТься з результатами нашого дослідження. Але, на відміну від наших результатів, у дослідженні Атаходжаєвої Г. А. і співавт. у хворих з СН без проявів метаболічного синдрому встановлено підвищення симпатовагального співвідношення (LF/HF), що поєднувалось зі зниженням LF. Автори дослідження обґрунтували такі результати наявністю так званого «парадоксу» LF при симптомній CH, який можна пояснити розвитком десенситизації адренорецепторів та зниженням чутливості барорецепторів за рахунок структурно-метаболічних змін у міокар-

\section{ЛІТЕРАТУРА}

1. ESC Guidelines at al. for the diagnosis and treatment of acute and chronic heart failure / P. Ponikowski, A. Voors, S. Anker [et al.] // European Heart Journal. 2016. - No. 37. - P. 2129-2200.

2. Maggioni A. Epidemiology of Heart Failure in Europe / A. Maggioni. // Heart Failure Clinics. - 2015. No. 11. - P. 625-635.

3. Gladden J. Heart failure with preserved ejection fraction / J. Gladden, W. Linke, M. Redfield // European Journal of Physiology. - 2014. - No. 466. - P. 1037-1053.

4. Cardiac diastolic and autonomic dysfunction are aggravated by central chemoreflex activation in heart failure with preserved ejection fraction rats / C. Toledo, D. Andrade, C. Lucero [et al.] // The Journal of Physiology. -

\section{REFERENCES}

1. Ponikowski, P., Voors, A., Anker, S., Bueno, H., Cleland, J., Coats, A., Falk, V. et al. (2016). 2016 ESC Guidelines for the diagnosis and treatment of acute and chronic heart failure. European Heart Journal, 37 (27), 2129-2200.

2. Maggioni, A. (2015). Epidemiology of Heart Failure in Europe. Heart Failure Clinics, 11(4), 625-635.

3. Gladden, J., Linke, W. \& Redfield, M. (2014). Heart failure with preserved ejection fraction. European Journal of Physiology, 466 (6), 1037-1053.

4. Toledo, C., Andrade, D., Lucero, C., Arce-Alvarez, A., Díaz, H., Aliaga, V., Schultz, H. et al. (2017). Cardiac diastolic and autonomic dysfunction are aggravated by central chemoreflex activation in heart failure with preserved ejection fraction rats. The Journal of Physiology, 595 (8), 24792495. ді, що може маскувати прогресуюче погіршення нейрогуморальної регуляції. Відмінність у результатах нашого дослідження та дослідження Атаходжаєвої Г. А. і співавт. можна пояснити включенням у дослідження хворих зі зниженою ФВ та більш тяжкими ступенями $\mathrm{CH}$.

Висновки. 1. Розвиток хронічної серцевої недостатності зі збереженою фракцією викиду супроводжується зниженням загальної варіабельності серцевого ритму.

2. У хворих з серцевою недостатністю зі збереженою фракцією викиду, порівняно зі здоровими особами, спостерігається зниження тонусу парасимпатичної ланки вегетативної нервової системи і збільшення тонусу симпатичної вегетативної ланки.

3. За результатами однофакторного регресійного аналізу встановлено взаємозв'язок спектрального показника SDNN та часу ізоволюметричного розслаблення.

Перспективи подальших досліджень. 3 огляду на отримані у нашому дослідженні результати необхідним $є$ подальше дослідження значення частотних та спектральних показників ВСР у прогнозуванні прогресування СН, у тому числі СНзЗФВ.

2017. - No. 595. - P. 2479-2495.

5. A new approach to detect congestive heart failure using short-term heart rate variability measures / G. Liu, L. Wang, Q. Wang [et al.] // PLoS ONE. - 2014. - No. 9. P. 93-99.

6. Changes in autonomic balance in patients with decompensated chronic heart failure / A. Rydlewska, E.Jankowska, B. Ponikowska [et al.] // Clinical Autonomic Research. - 2011. - No. 21. - P. 47-54.

7. Атаходжаева Г. А. Вариабельность ритма сердца у больных с хронической сердечной недостаточностью и метаболическим синдромом / Г. А. Атаходжаева, Ш. М. Рахимов, Н. З. Азимов // Врачебное дело. - 2017. № 3. - C. 31-37.

5. Liu, G., Wang, L., Wang, Q., Zhou, G., Wang, Y. and Jiang, Q. (2014). A new approach to detect congestive heart failure using short-term heart rate variability measures. PLOS ONE, 9 (4), 93-99.

6. Rydlewska, A., Jankowska, E., Ponikowska, B., Borodulin-Nadzieja, L., Banasiak, W. \& Ponikowski, P. (2011). Changes in autonomic balance in patients with decompensated chronic heart failure. Clinical Autonomic Research, 21 (1), 47-54.

7. Atakhodzhayeva, G.A., Rakhimov, Sh.M., \& Azimov, N.Z. (2017). Variabelnost ritma serdtsa u bolnykh s khronicheskoy serdechnoy nedostatochnostyu i metabolicheskim sindromom [Variability of heart rate in patients with chronic heart insufficiency]. Vrachebnoe delo - Medical Case, 3-4, 31-37 [in Russian]. 


\title{
Огляди літератури, оригінальні дослідження, погляд на проблему \\ ВАРИАБЕЛЬНОСТЬ СЕРДЕЧНОГО РИТМА ПРИ ХРОНИЧЕСКОЙ СЕРДЕЧНОЙ НЕДОСТАТОЧНОСТИ С СОХРАНЕННОЙ ФРАКЦИЕЙ ВЫБРОСА
}

\author{
๑я. А. Андреева, Д. П. Мирный \\ ГЗ «Запорожская медицинская академия последипломного образования Мз Украины»
}

РЕзЮМЕ. Сердечная недостаточность остаётся основной причиной преждевременной смерти и низкого качества жизни у пациентов с различными кардиоваскулярными заболеваниями.

Цель - изучить изменения вариабельности сердечного ритма у больных сердечной недостаточностью с сохранённой фракцией выброса.

Материал и методы. Обследовано 98 человек с СНсСФВ І-ІІА стадии I-ІІ функциональных классов по классификации NYHA (53 мужчин и 45 женщин) в возрасте от 19 до 66 лет. Всем участникам исследования проведены общее клиническое обследование с обязательным измерением окружности талии и бёдер, веса и роста, эхокардиография, суточное мониторирование ЭКГ.

Результаты. У всех пациентов с СНсСФВ были зарегистрированы изменения ВСР в течение суток и ригидный циркадный ритм ЧСС. Наблюдалось патологическое увеличение спектральных показателей VLF, LF, LFN как в дневное, так и в ночное время. Достаточного снижения спектральных показателей VLF, LF, LFN в ночное время в основной группе не происходило. Не фиксировался достаточный подъём HF и HFN в ночное время, в отличие от контрольной группы. Соотношение LF/HF было достоверно увеличено у больных с CHсCФВ. При корреляционном анализе установлена отрицательная корреляционная связь возраста с SDNN ( $r=-0,336, p<0,05)$, RMSSD $(r=-0,312, p<0,05)$, pNN50 ( $r=-0,377, p<0,05)$, HF $(r=-0,418, p<0,05)$ и положительная корреляционная связь c LF/HF $(r=0,384, p<0,05)$. SDNN коррелировал с временем замедления кровотока раннего диастолического наполнения левого желудочка ( $\ulcorner=-0,418$, $\mathrm{p}<0,05)$ и временем изоволюметрического расслабления $(r=-0,436, p<0,05)$.

Выводы. Развитие хронической сердечной недостаточности с сохранённой фракцией выброса сопровождается снижением общей вариабельности сердечного ритма. У больных с сердечной недостаточностью с сохраненной фракцией выброса, по сравнению со здоровыми лицами, наблюдается снижение тонуса парасимпатического звена вегетативной нервной системы и увеличение тонуса симпатического вегетативного звена. По результатам однофакторного регрессионного анализа установлена взаимосвязь спектрального показателя SDNN и времени изоволюметрического расслабления.

КЛЮчЕВЫЕ СЛОВА: сердечная недостаточность; сердечный ритм; фракция выброса; нервная система.

\section{HEART RATE VARIABILITY IN CHRONIC HEART FAILURE WITH PRESERVED EJECTION FRACTION}

\section{@I. O. Andreieva, D. P. Myrnyi Zaporizhzhia Medical Academy of Post-Graduate Education}

SUMMARY. Heart failure remains the main cause of premature death and poor quality of life in patients with different cardiovascular diseases.

The aim of the study - to investigate changes in the heart rate variability in patients with heart failure with a preserved ejection fraction.

Material and Methods. 98 patients (53 men and 45 women) aged 19 to 66 years with HFpEF of I-IIA stages and I-II functional classes according to the classification of NYHA were examined. All participants of the study had a general clinical examination with obligatory measurements of the circumference of the waist and hips, weight, and height, echocardiography, daily monitoring of the ECG.

Results. Changes in HRV and rigid circadian rhythm of heart rate during day and overnight in all patients with HFpEF were recorded. There was a pathological increase in the spectral indices of VLF, LF, LFN both in the daytime and at night. There was no significant decrease in VLF, LF, LFN spectrum at night at the main group. There was no significant increase in HF and HFN at night, as opposed to the control group. The LF/HF ratio was significantly increased in patients with HFpEF. Correlation analysis revealed a negative correlation between age and SDNN $(r=-0.336, p<0.05), R M S S D(r=-0.312$, $p<0.05)$, pNN50 ( $r=-0.377, p<0,05), \mathrm{HF}(r=-0.418, p<0.05)$ and a positive correlation with the ratio of $L F / H F(r=0.384$, $p<0.05)$. SDNN correlated with the time of IVRT $(r=-0.418, p<0.05)$ and DT $(r=-0.436, p<0.05)$.

Conclusions. The development of chronic heart failure with a preserved ejection fraction is accompanied by a decrease in the overall heart rate variability. There is a decrease in the tone of the parasympathetic autonomic nervous system and an increase in the sympathetic autonomic nervous system in patients with heart failure with a preserved ejection fraction compared to healthy individuals. According to the results of invariant regression analysis, the relationship of the spectral index SDNN with the DT was established.

KEY WORDS: heart failure; heart rate; fraction of release; nervous system. 